\title{
Effects of endplate coverage and intervertebral height change on heterotopic ossification following cervical disc replacement
}

\author{
Yi-Wei Shen ${ }^{1 \dagger}$, Yi Yang ${ }^{1 \dagger}$, Hao Liu ${ }^{1 *} \mathbb{B}$, Xin Rong ${ }^{1}$, Chen Ding ${ }^{1}$, Yang Meng ${ }^{1}$, Bei-Yu Wang ${ }^{1}$ and Ying Hong ${ }^{2}$
}

\begin{abstract}
Background: Heterotopic ossification ( $\mathrm{HO})$ is a common complication after cervical disc replacement (CDR). Biomechanical factors including endplate coverage and intervertebral disc height change may be related to HO formation. However, there is a dearth of quantitative analysis for endplate coverage, intervertebral height change and their combined effects on $\mathrm{HO}$.

Methods: Patients who underwent single-level or two-level CDR with Prestige-LP were retrospectively reviewed. Clinical outcomes were evaluated through Japanese Orthopaedic Association (JOA) score, Neck Disability Index (NDI) score, and visual analogue scale (VAS) score. Radiological data, including the prosthesis-endplate depth ratio, intervertebral height change, posterior heterotopic ossification (PHO) and angular parameters, were collected. Logistic regression analysis was used to identify the potential risk factors. Receiver operating characteristic curves were plotted and the cut-off values of each potential factors were calculated.

Results: A total of 138 patients with 174 surgical segments were evaluated. Both the prosthesis-endplate depth ratio $(P<0.001)$ and post-operative disc height change $(P<0.001)$ were predictive factors for $\mathrm{PHO}$ formation. The area under the curve (AUC) of the prosthesis-endplate depth ratio, disc height change and their combined effects represented by the combined parameter (CP) were $0.728,0.712$ and 0.793 , respectively. The risk of $\mathrm{PHO}$ significantly increased when the prosthesis-endplate depth ratio $<93.77 \%(P<0.001, \mathrm{OR}=6.909,95 \% \mathrm{Cl} 3.521-13.557)$, the intervertebral height change $\geq 1.8 \mathrm{~mm}(P<0.001, \mathrm{OR}=5.303,95 \% \mathrm{Cl} 2.592-10.849)$, or the $\mathrm{CP}$ representing the combined effect $<84.88$ $(P<0.001, \mathrm{OR}=10.879,95 \% \mathrm{Cl} 5.142-23.019)$.

Conclusions: Inadequate endplate coverage and excessive change of intervertebral height are both potential risk factors for the PHO after CDR. Endplate coverage less than 93.8\% or intervertebral height change more than $1.8 \mathrm{~mm}$ would increase the risk of $\mathrm{PHO}$. The combination of these two factors may exacerbate the non-uniform distribution of stress in the bone-implant interface and promote $\mathrm{HO}$ development.
\end{abstract}

Keywords: Cervical disc replacement, Heterotopic ossification, Endplate coverage, Intervertebral height change

*Correspondence: liuhao6304@126.com

${ }^{\dagger}$ Yi-Wei Shen and Yi Yang have contributed equally to this work

1 Department of Orthopedic Surgery, West China Hospital, Sichuan University, No. 37 Guo Xue Rd, Chengdu 610041, China

Full list of author information is available at the end of the article

\section{Introduction}

Anterior cervical discectomy and fusion (ACDF) has been the standard procedure concerning surgical treatment for cervical myelopathy or radiculopathy for several decades. Although advances in implants and surgical techniques of ACDF have led to better outcomes and fewer complications, the fusion procedure sacrifices the segmental mobility and alters the biomechanical status of adjacent original author(s) and the source, provide a link to the Creative Commons licence, and indicate if changes were made. The images or other third party material in this article are included in the article's Creative Commons licence, unless indicated otherwise in a credit line to the material. If material is not included in the article's Creative Commons licence and your intended use is not permitted by statutory regulation or exceeds the permitted use, you will need to obtain permission directly from the copyright holder. To view a copy of this licence, visit http://creativecommons.org/licenses/by/4.0/. The Creative Commons Public Domain Dedication waiver (http://creativeco mmons.org/publicdomain/zero/1.0/) applies to the data made available in this article, unless otherwise stated in a credit line to the data. 
intervertebral discs, which may accelerate adjacent segmental pathology with or without symptoms [1]. Cervical disc replacement (CDR) is an effective option for patients diagnosed as cervical myelopathy or radiculopathy. Previous randomized controlled studies with long-term results have demonstrated that CDR has at least equivalent clinical outcomes compared to ACDF, with lower incidence of adjacent segment disease (ASD) [2-5]. However, heterotopic ossification (HO), also known as paravertebral ossification or post-operative bone formation, occurred as one of the major complications of CDR [6-8]. HO is considered an intractable issue probably resulting in the loss of segmental mobility and poor neurological recovery $[9,10]$.

The formation of HO following CDR is multifactorial, including the preoperative ossification, surgical technique and biomechanical elements $[11,12]$. The change of biomechanical environment of the surgical segment caused by artificial disc implantation is one of the major considerations of $\mathrm{HO}$ formation. Ganbat et al. [13] found that $\mathrm{HO}$ formation might play a role in compensating for the non-uniform stress distribution of prosthesis-endplate interface after CDR. Biomechanical factors, including endplate coverage and disc height, may play roles in this process [14]. Prior studies suggested that insufficient endplate coverage could lead to the occurrence of HO [1517]. However, due to the fixed size of prosthesis and the irregular morphology of cervical endplate, the endplate coverage may not be always optimal during operation. There is a dearth of quantitative analysis for the relationship between endplate coverage and $\mathrm{HO}$ occurrence for intraoperative reference. Besides, Kim et al. [18] found that over-distraction of surgical segment and increase in the segmental mobility would affect the HO formation. Inappropriate increment of intervertebral height would further increase the stress of prosthesis-endplate interface in the scenario of insufficient endplate coverage [19]. However, studies about the combined effects of endplate coverage and disc height change on $\mathrm{HO}$ formation are still scarce. Several retrospective studies reported that insufficient coverage of endplate may induce $\mathrm{HO}$ formation while the effect of intervertebral disc height change was not analysed $[12,15,16,20]$. Additionally, other studies emphasized the effect of disc height on $\mathrm{HO}$ formation while the endplate coverage was not scrutinized [21, 22]. Therefore, this study aimed to investigate the effects of endplate coverage and intervertebral disc height change post-operatively and the combination of these two factors on $\mathrm{HO}$ formation following CDR through quantitative analysis.

\section{Methods}

\section{Patient population}

This retrospective study included patients who underwent 1-level and 2-level Prestige-LP CDR from January
2010 to January 2019 with a minimum of 2 years follow-up. The study protocol was approved by the Medical Ethical Committee of West China Hospital of Sichuan University and all patients provided written informed consent. Patients were included if they (1) were 18-65 years of age; (2) were diagnosed as 1-level or 2-level cervical degenerative disc disease causing symptomatic radiculopathy or myelopathy between $\mathrm{C} 3$ and C7; and (3) failed strict conservative therapy for at least 12 weeks. The exclusion criteria included: (1) instability, irreducible kyphosis, or severe degeneration at the surgical segment; (2) prior history of cervical spine surgery; (3) patients diagnosed as non-degenerative cervical spine diseases; (4) ossification of the posterior longitudinal ligament; (5) osteoporosis.

\section{Surgical procedure}

The same senior spine surgeon treated all the patients. A standard right-side Smith-Robinson approach was performed after general anaesthesia. Complete discectomy and decompression were conducted at the index level by removing the anterior longitudinal ligament, disc tissue, posterior longitudinal ligament and osteophytes, followed by careful endplate preparation with a high-speed burr. Then, a rail cutter guide and bit were used to drill the fixation channels in the endplate, and an appropriate Prestige-LP disc was inserted into the indicated level. Proper placement of the prosthesis was verified by $\mathrm{C}$-arm fluoroscopy. Copious irrigation with normal saline and meticulous haemostasis were conducted. The same procedure was performed at the other level in 2-level cases. Finally, the incision was sutured layer by layer after inserting a drainage tube. Nonsteroidal anti-inflammatory drugs were not routinely used for preventing $\mathrm{HO}$ in this cohort.

\section{Data collection and measurement}

Clinical and radiological data were collected preoperatively, 1 week post-operatively and at last follow-up. Clinical outcomes were evaluated through Japanese Orthopaedic Association (JOA) score, Neck Disability Index (NDI) functional score, and visual analogue scale (VAS) score.

$\mathrm{HO}$ and anterior bone loss (ABL) were assessed on the lateral X-rays at the last follow-up. Due to the anterior-limiting design of Prestige-LP disc, inadequate coverage of endplate predominantly occurred in the posterior endplate region. Thus, only posterior heterotopic ossification (PHO) was assessed in this study. According to the McAfee classification, Grade 3-4 was classified as motion-restricting $\mathrm{HO}$. ABL was defined as the reduction in subchondral vertebral body length during follow-up compared with the 
post-operative lateral radiograph as previous study described [23]. Disc height was measured at the lateral radiograph before and after surgery (Fig. 1a, b). The prosthesis-endplate depth ratio was calculated on the median sagittal plane of reconstruction computed tomography $(\mathrm{CT})$ as dividing the length of the prosthesis by the immediate post-operative length of the endplate [15] (Fig. 1c). Cervical lordosis was the angle formed between the inferior endplate of $\mathrm{C} 2$ vertebra and the inferior endplate of $\mathrm{C} 7$ vertebra. $\mathrm{C} 2-\mathrm{C} 7$ range of motion (ROM) were measured on the flexion and extension radiographs using the Cobb method. Shell angle was defined as the angle drawn from the superior and inferior endplate of the prosthesis. Functional spinal unit (FSU) angulation was the angle between the lines of superior endplate of cranial vertebral body and the inferior endplate of the caudal vertebral body at the indicated segment. Endplate angle of the cranial vertebra was recorded as the angle between the upper and lower endplates of the cranial vertebral body at index level. The changes of endplate angle between pre-operation and 1 week post-operatively were defined as the milling angle. The change in disc insertion angle was defined as the difference of endplate angle between pre-operation and last follow-up, representing the degree to which the inserted prosthesis deviates from the natural disc position [24] (Fig. 1).

\section{Statistical analysis}

All statistical analyses were performed using SPSS Version 25.0 software (IBM Corp., Armonk, New York, USA). The results were presented as mean \pm standard deviation for continuous variables and number of cases for categorical variables. Comparison of parameters between pre- and post-operation was conducted using paired $t$ test. The independent $t$ test or the Mann-Whitney $U$ test was used to compare continuous variables depending on the normality of data. The Chi-square or Fisher's exact test was used for categorical variables. Potential risk factors with $P<0.05$ or those with clinical significance were involved in the logistic regression analysis. Receiver operating characteristic (ROC) curves of each variable were calculated. A 2 -tailed $P$ values $<0.05$ were considered statistically significant.

\section{Results}

\section{Demographic data}

In total, 138 patients and 174 arthroplasty levels with at least 2-year follow-up were involved in this retrospective study, including 66 male and 72 female, with a mean age of 43.59 (range, 26-65) years. The median follow-up time was 42 (range, 24-131) months. As shown in Table 1, PHO was detected in 73 segments and 25 motionrestricting PHO identified (Fig. 2). Neither the depth nor the height of prosthesis between groups with and without

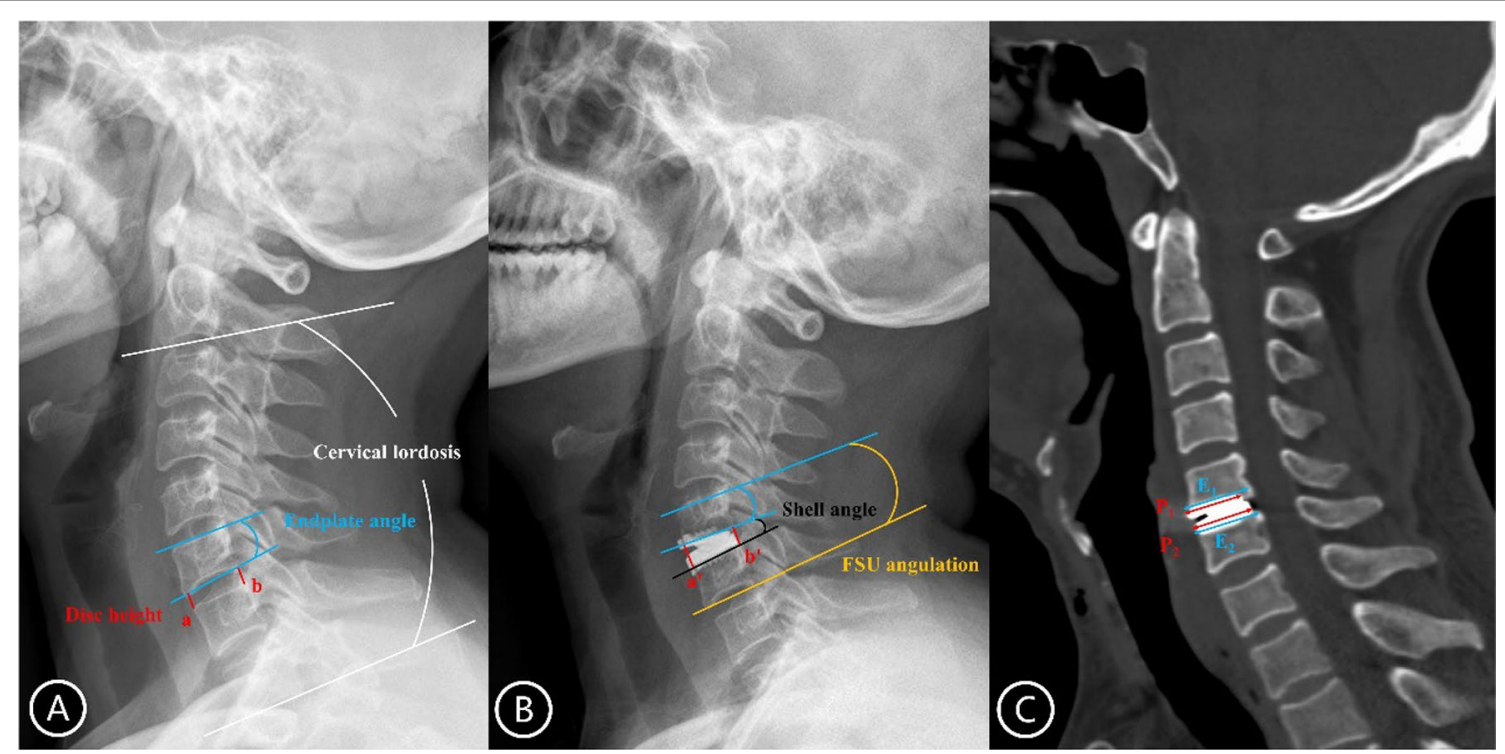

Fig. 1 Measurement of radiological parameters. A, B Post-operative change of intervertebral disc height is calculated as $\left(a^{\prime}+b^{\prime}\right) / 2-(a+b) / 2$. Cervical lordosis is defined as the angle between the inferior endplate of C2 vertebra and the inferior endplate of C7 vertebra. Endplate angle of the cranial vertebra is the angle between the upper and lower endplates of the cranial vertebral body at index level. Shell angle is recorded as the angle between the superior and inferior endplate of the prosthesis. FSU angulation is the angle between the superior endplate of cranial vertebral body and the inferior endplate of the caudal vertebral body at the indicated segment. C Prosthesis-endplate depth ratio is calculated as $\left(P_{1} / E_{1}+P_{2} / E_{2}\right) / 2$. FSU, functional spinal unit 
Table 1 Comparison of characteristics between levels with and without posterior heterotopic ossification

\begin{tabular}{|c|c|c|c|}
\hline & non-PHO $(n=101)$ & PHO $(n=73)$ & $P$ value \\
\hline No. of patients, $n$ & 74 & 64 & - \\
\hline \multicolumn{4}{|l|}{ No. of surgical levels, $n$} \\
\hline Single-level & 59 & 43 & 0.949 \\
\hline Level distribution & & & 0.516 \\
\hline $\mathrm{C} 3 / 4$ & 7 & 3 & \\
\hline$C 4 / 5$ & 17 & 18 & \\
\hline $\mathrm{C} 5 / 6$ & 62 & 44 & \\
\hline $\mathrm{C} 6 / 7$ & 15 & 8 & \\
\hline Age, years & $43.10 \pm 7.94$ & $45.23 \pm 8.41$ & 0.110 \\
\hline $\operatorname{Sex}(M / F)$ & $47 / 54$ & $38 / 35$ & 0.472 \\
\hline $\mathrm{BMl}$ & $23.43 \pm 2.87$ & $23.36 \pm 2.39$ & 0.884 \\
\hline Blood loss, ml & $53.81 \pm 28.05$ & $53.84 \pm 34.27$ & 0.647 \\
\hline Follow-up, months & $48.43 \pm 20.62$ & $55.97 \pm 28.23$ & 0.276 \\
\hline Milling angle & $0.89 \pm 3.52$ & $0.83 \pm 4.12$ & 0.590 \\
\hline Mean depth of prosthesis, $\mathrm{mm}$ & 15.31 & 15.42 & 0.686 \\
\hline Mean height of prosthesis, $\mathrm{mm}$ & 5.61 & 5.63 & 0.980 \\
\hline Prosthesis-endplate depth ratio, $\%$ & $94.92 \pm 3.26$ & $92.13 \pm 3.75$ & $<0.001^{*}$ \\
\hline Post-operative disc height change, $\mathrm{mm}$ & $1.76 \pm 0.99$ & $2.56 \pm 1.04$ & $<0.001^{*}$ \\
\hline Anterior bone loss & 62 & 45 & 0.973 \\
\hline
\end{tabular}

PHO, posterior heterotopic ossification

*Significant difference between two groups

PHO showed significant differences. No significant differences were noted in the milling angle. The prosthesisendplate depth ratio in non-PHO group was significantly higher than PHO group $(94.92 \pm 3.26 \%$ vs. $92.13 \pm 3.75 \%$, $P<0.001)$. Significantly higher post-operative intervertebral height change was also observed in PHO levels compared to non-PHO levels $(2.56 \pm 1.04 \mathrm{~mm}$ vs. $1.76 \pm 0.99 \mathrm{~mm}, P<0.001)$. There was no significant difference in the incidence of ABL between the two groups. The patient-reported clinical outcomes including JOA, NDI and VAS showed significant improvement at last follow-up and the scores were comparable between patients with and without PHO (Table 2).

\section{Radiological outcomes}

The angular parameters of levels with and without PHO were compared as shown in Table 3. No significant differences of parameters of post-operation and changes during follow-up were observed. At last follow-up, C2C7 ROM $(P=0.035)$ and ROM at index level $(P=0.004)$ were significantly lower at levels with $\mathrm{PHO}$ compared to non-PHO levels.

Logistic regression analysis confirmed that both the prosthesis-endplate depth ratio $(P<0.001, B=-0.279$, $\mathrm{OR}=0.757,95 \%$ confidence interval $[\mathrm{CI}]$ 0.678-0.844) and post-operative intervertebral height change $(P<0.001, B=0.926, \mathrm{OR}=2.523,95 \%$ confidence interval
[CI 1.700-3.746) were predictive factors for the occurrence of PHO (Table 4). According to the logistic regression coefficient, a combined parameter (CP) of two predictive factors was defined as the prosthesis-endplate depth ratio- $0.926 / 0.279 \times$ disc height change, representing the combined effect of endplate coverage and intervertebral height change. A larger $\mathrm{CP}$ may denote less biomechanical changes of surgical segment caused by the prosthesis implanting, with optimal endplate coverage and slight change of intervertebral space height. The area under the curve (AUC) of the prosthesis-endplate depth ratio, intervertebral height change and $\mathrm{CP}$ were 0.728 (95\% confidence interval [CI] 0.650-0.807), 0.712 (95\% confidence interval [CI] 0.635-0.789) and 0.793 (95\% confidence interval [CI] 0.724-0.863), respectively (Fig. 3). The cut-off values for three factors were 93.77, 1.80 , and 84.88 , respectively.

The influences of prosthesis-endplate depth ratio, intervertebral height change and $\mathrm{CP}$ were further investigated by dividing the factors into lower and higher groups based on cut-off values. As shown in Table 5, the risk of PHO was significantly increased when the $\mathrm{P}-\mathrm{E}$ depth ratio $<93.77 \%(P<0.001, \mathrm{OR}=6.909,95 \%$ confidence interval [CI] 3.521-13.557). The difference of post-operative ROM at the index level between the lower $\mathrm{P}-\mathrm{E}$ depth ratio group and higher P-E depth ratio was statistically significant $\left(7.77 \pm 3.89^{\circ}\right.$ vs. $6.73 \pm 3.57^{\circ}$, 


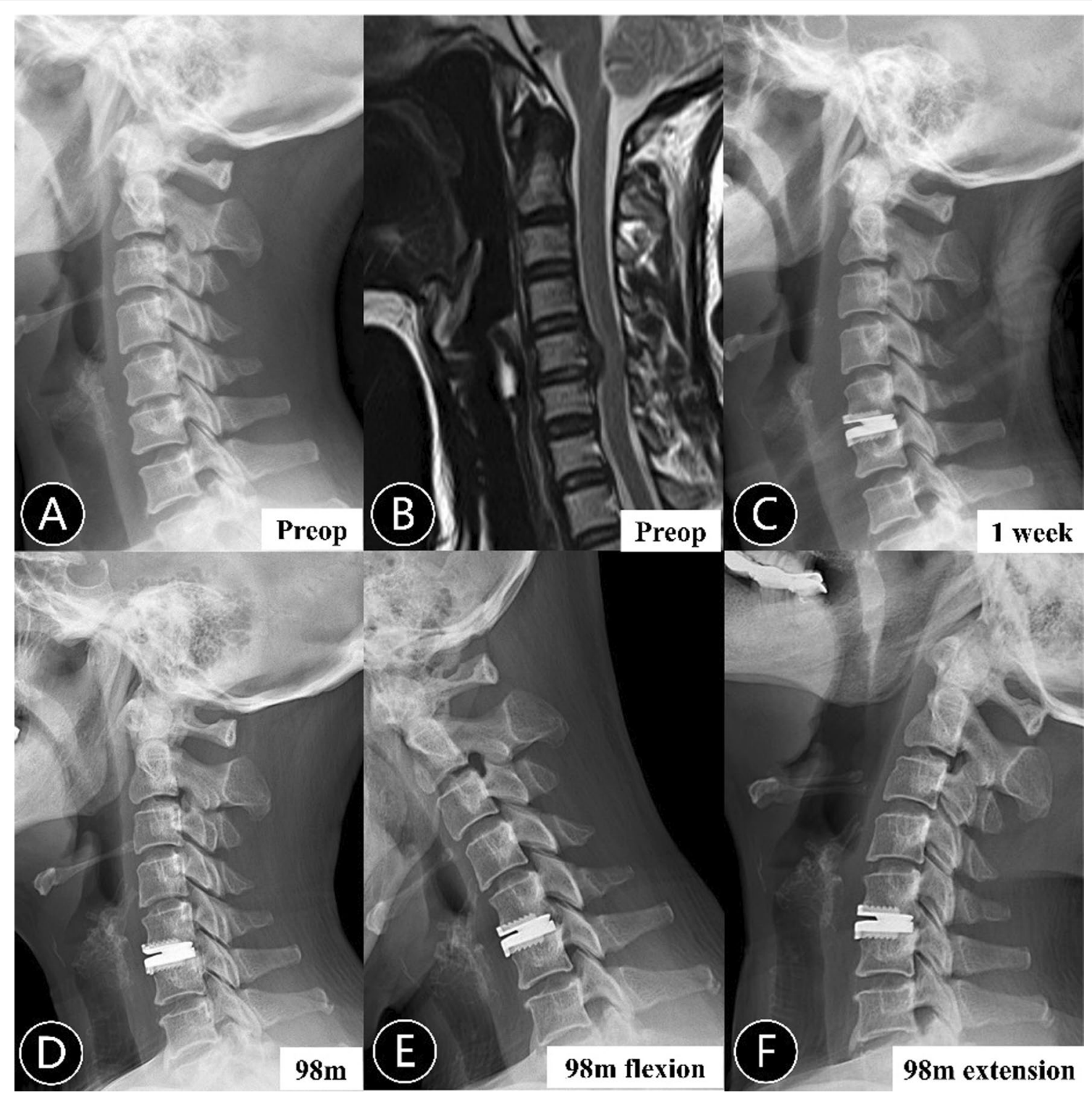

Fig. 2 Radiograph of a 50-year-old woman. A, B Preoperative lateral radiograph and MRI showed decreased intervertebral disc height and compression at C5/6. C Lateral radiograph at 1 week after surgery showed a recovery of intervertebral disc height and insufficient endplate coverage at the index level. D-F X-rays at 98 months follow-up suggested posterior heterotopic ossification with motion preservation at C5/6

$P=0.040)$. The $\mathrm{C} 2-\mathrm{C} 7 \mathrm{ROM}$ and ROM at index level were significantly lower in the poor endplate coverage group. Significant larger change in disc insertion angle was observed in the higher $\mathrm{P}-\mathrm{E}$ ratio group compared with lower $\mathrm{P}-\mathrm{E}$ ratio group $\left(1.77 \pm 3.51^{\circ}\right.$ vs. $0.63 \pm 4.29^{\circ}$, $P=0.039)$. The incidence of ABL did not show significant difference between the groups. The effect of disc height change is presented in Table 6. The incidence of PHO was significantly higher in the group with disc height change $>1.80 \mathrm{~mm} \quad(P<0.001, \mathrm{OR}=5.303,95 \%$ confidence interval [CI] 2.592-10.849). At last followup, significant better lordosis of cervical spine was noted in the higher disc height change group compared with the other group $\left(13.27 \pm 8.37^{\circ}\right.$ vs. $9.93 \pm 8.90^{\circ}$, $P=0.013)$. No significant difference was observed in the ROM and ABL. The changes of shell angle during follow-up showed significant difference between two groups $\left(-2.03 \pm 3.77^{\circ}\right.$ vs. $\left.-3.51 \pm 4.16^{\circ}, P=0.019\right)$. As suggested in Table $7, \mathrm{CP}<84.88$ was a significant risk factor for PHO $(P<0.001$, OR $=10.879,95 \%$ confidence interval [CI] 5.142-23.019). Similar to the comparison of different P-E depth ratio groups, significant differences were noted in the ROM at index level post-operatively $(P=0.029)$, ROM of $\mathrm{C} 2-\mathrm{C} 7(P=0.018)$ and ROM 
Table 2 Clinical outcomes of patients with and without posterior heterotopic ossification

\begin{tabular}{lccc}
\hline & $\begin{array}{l}\text { Patients without } \\
\text { PHO }(\boldsymbol{n}=\mathbf{7 4})\end{array}$ & $\begin{array}{l}\text { Patients with } \\
\text { PHO }(\boldsymbol{n}=\mathbf{6 4})\end{array}$ & P value \\
\hline $\begin{array}{l}\text { JOA score } \\
\quad \text { Preoperative } \\
\text { Last follow-up }\end{array}$ & $12.12 \pm 0.83$ & $12.14 \pm 0.96$ & 0.809 \\
NDI score & $16.04 \pm 0.73^{*}$ & $15.95 \pm 0.67^{*}$ & 0.392 \\
$\quad \begin{array}{l}\text { Preoperative } \\
\text { Last follow-up }\end{array}$ & $22.39 \pm 3.13$ & $22.55 \pm 3.51$ & 0.755 \\
VAS score & $5.64 \pm 0.61^{*}$ & $5.66 \pm 0.60^{*}$ & 0.649 \\
$\quad$ & & \\
$\quad$ Preoperative & $5.89 \pm 0.48$ & $5.86 \pm 0.53$ & 0.819 \\
Last follow-up & $1.53 \pm 0.50^{*}$ & $1.61 \pm 0.49^{*}$ & 0.332 \\
\hline
\end{tabular}

PHO, posterior heterotopic ossification; JOA, Japanese Orthopedic Association; $\mathrm{NDI}$, neck disability index; VAS, visual analogue scale

${ }^{*} P<0.05$, compared with pre-operation

Table 3 Angular parameters of levels with and without posterior heterotopic ossification

\begin{tabular}{lccl}
\hline & non-PHO $(\boldsymbol{n}=\mathbf{1 0 1})$ & PHO $(\boldsymbol{n}=\mathbf{7 3})$ & $\boldsymbol{P}$ value \\
\hline Post-op & & & \\
Cervical lordosis & $13.34 \pm 9.90$ & $14.32 \pm 11.21$ & 0.541 \\
C2-C7 ROM & $28.35 \pm 11.03$ & $29.35 \pm 11.53$ & 0.711 \\
Shell angle & $4.99 \pm 4.91$ & $4.08 \pm 5.18$ & 0.239 \\
FSU angulation & $2.40 \pm 4.30$ & $3.33 \pm 5.23$ & 0.217 \\
ROM at index level & $7.10 \pm 3.82$ & $7.37 \pm 3.66$ & 0.533 \\
Last follow-up & & & \\
Cervical lordosis & $11.35 \pm 8.63$ & $12.85 \pm 8.79$ & 0.264 \\
C2-C7 ROM & $50.79 \pm 13.45$ & $46.33 \pm 13.95$ & $0.035^{*}$ \\
Shell angle & $2.16 \pm 5.06$ & $0.97 \pm 4.97$ & 0.125 \\
FSU angulation & $-0.47 \pm 4.47$ & $0.47 \pm 5.06$ & 0.200 \\
ROM at index level & $9.12 \pm 4.94$ & $7.06 \pm 4.51$ & $0.004^{*}$ \\
Changes during follow- & & & \\
up & & & \\
Cervical lordosis & $-1.99 \pm 9.03$ & $-1.47 \pm 9.08$ & 0.712 \\
Shell angle & $-2.82 \pm 3.78$ & $-3.10 \pm 4.46$ & 0.659 \\
FSU angulation & $-2.87 \pm 3.63$ & $-2.86 \pm 3.63$ & 0.988 \\
Insertion angle & $1.37 \pm 3.87$ & $1.06 \pm 4.01$ & 0.144 \\
\hline
\end{tabular}

PHO, posterior heterotopic ossification; post-op, values at 1 week after surgery; FSU, functional spinal unit angle; ROM, range of motion

*Significant difference between two groups

at index level $(P=0.004)$ between the two groups. The incidence of $\mathrm{ABL}$ was comparable in the two groups.

\section{Discussion}

In the treatment of cervical radiculopathy and myelopathy, CDR is introduced to reconstruct the physiological motion of diseased segment. The formation of $\mathrm{HO}$ after CDR is one of the major obstacles in the development of non-fusion technique of cervical surgery. However,
Table 4 Logistic regression analysis for posterior heterotopic ossification

\begin{tabular}{lcccc}
\hline & $P$ value & $B$ & OR & $\mathbf{9 5 \%} \mathbf{C l}$ \\
\hline $\begin{array}{l}\text { Prosthesis-endplate depth } \\
\text { ratio }\end{array}$ & $<0.001^{*}-0.279$ & 0.757 & $0.678-0.844$ \\
Intervertebral height change & $<0.001^{*}$ & 0.926 & 2.523 & $1.700-3.746$ \\
Follow-up time & 0.644 & 0.004 & 1.004 & $0.988-1.020$ \\
Age & 0.205 & 0.029 & 1.029 & $0.984-1.076$ \\
\hline
\end{tabular}

* Statistical significance

the detailed mechanism of $\mathrm{HO}$ is still controversial. The change of biomechanical environment is considered a main contributing factor. $\mathrm{HO}$ formation is postulated to be a self-defence mechanism responding to the nonphysiological biomechanics of cervical spine after CDR, which is influenced by the endplate coverage and disc height $[14,25]$. The present study focused on the effects of endplate coverage, intervertebral height change and their combined effect on $\mathrm{HO}$ formation. Previous study has suggested an evidently higher incidence of $\mathrm{HO}$ in the posterior disc space and different risk factors for $\mathrm{HO}$ in the anterior and posterior disc space [26]. Therefore, only PHO was taken into consideration in this study due to the anterior-limiting design of Prestige-LP disc. The results suggested that the occurrence of PHO did not affect the patient-reported outcomes. This is consistent with prior studies, suggesting that the satisfactory outcomes of CDR mainly depend on adequate surgical decompression $[10,27,28]$. Both prosthesisendplate depth ratio and intervertebral height change were potential risk factors for the development of $\mathrm{PHO}$ after CDR. The risk of PHO significantly increased when the prosthesis-endplate depth ratio was less than $93.8 \%$ or the change of intervertebral disc height after surgery was large than $1.80 \mathrm{~mm}$.

Due to the irregularity of cervical endplate morphology, the mismatch between the prosthesis and endplate is usually unavoidable [29]. Thaler et al. [30] reported that $43.7 \%$ of Bryan and ProDisc-C, $60.4 \%$ of Discover, and $100 \%$ of Prestige footprints did not match the endplate regarding anterior-posterior diameters. Insufficient endplate coverage is thought to lead to the occurrence of HO. Tu et al. [12] retrospectively evaluated the perfectness of carpentry for each arthroplasty level with Bryan disc, which defined the inadequate endplate coverage and shell kyphosis of index level as suboptimal group. They found that the suboptimal carpentry group had significantly more high-grade $\mathrm{HO}$ ( $\geq$ Grade 2 ) than the optimal carpentry group. Zeng et al. [15] reported that the inadequate width and depth of the Prestige-LP relative to the endplate are likely to induce the formation of $\mathrm{HO}$. $\mathrm{Xu}$ et al. [17] concluded 


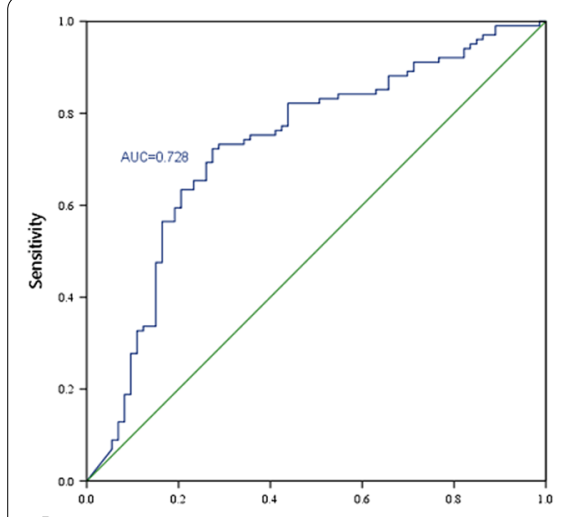

A

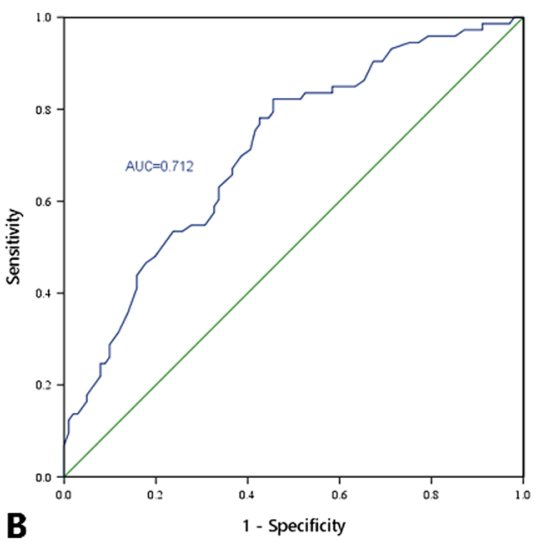

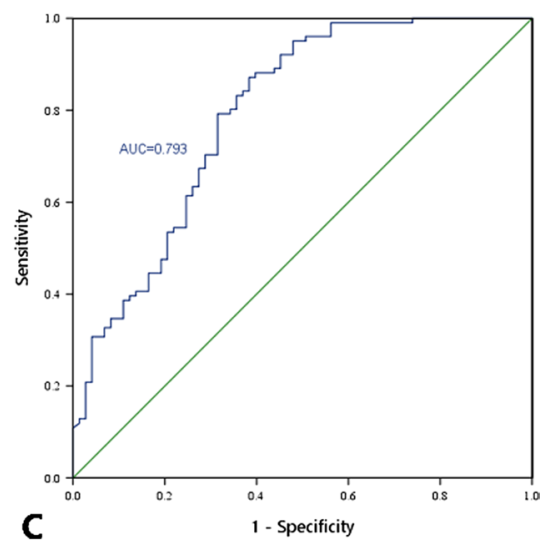

C

g. 3 ROC curve of prosthesis-endplate depth ratio $(\mathbf{A})$, intervertebral height change (B), and CP (C) for the prediction of posterior heterotopic ossification. The AUC are $0.728,0.712$, and 0.793 , respectively. ROC curve, receiver operating characteristic curve; CP, combined parameter; AUC, area under the curve

Table 5 Radiographic parameters between poor endplate coverage group and good endplate coverage group

\begin{tabular}{lccr}
\hline & $\begin{array}{l}\text { P-E depth } \\
\text { ratio } \\
(\boldsymbol{n}=\mathbf{8 1})\end{array}$ & $\begin{array}{l}\text { P-E depth } \\
\text { ratio } \geq \mathbf{9 3 . 7 7} \\
(\boldsymbol{n}=\mathbf{9 3})\end{array}$ & P value \\
\hline PHO & 53 & 20 & $<0.001^{*}$ \\
Motion-restricting PHO & 21 & 4 & 0.115 \\
Post-op & & & \\
Cervical lordosis & $13.07 \pm 10.31$ & $14.35 \pm 10.59$ & 0.621 \\
C2-C7 ROM & $28.01 \pm 12.12$ & $29.44 \pm 10.38$ & 0.229 \\
Shell angle & $4.29 \pm 5.03$ & $4.88 \pm 5.05$ & 0.612 \\
FSU angulation & $2.59 \pm 4.59$ & $2.96 \pm 4.85$ & 0.573 \\
ROM at index level & $7.77 \pm 3.89$ & $6.73 \pm 3.57$ & $0.040^{*}$ \\
Last follow-up & & & \\
Cervical lordosis & $11.11 \pm 8.92$ & $12.74 \pm 8.48$ & 0.219 \\
C2-C7 ROM & $44.94 \pm 14.47$ & $52.38 \pm 12.25$ & $<0.001^{*}$ \\
Shell angle & $1.50 \pm 5.43$ & $1.81 \pm 4.70$ & 0.687 \\
FSU angulation & $-0.11 \pm 4.87$ & $-0.04 \pm 4.64$ & 0.928 \\
ROM at index level & $7.31 \pm 5.00$ & $9.09 \pm 4.61$ & $0.003^{*}$ \\
Anterior bone loss & 44 & 63 & 0.070 \\
Changes during follow- & & & \\
up & & & 0.800 \\
Cervical lordosis & $-1.96 \pm 9.10$ & $-1.61 \pm 9.01$ & 0.649 \\
Shell angle & $-2.79 \pm 4.19$ & $-3.07 \pm 3.98$ & $0.039^{*}$ \\
FSU angulation & $-2.70 \pm 3.55$ & $-3.01 \pm 3.70$ & \\
Insertion angle & $0.63 \pm 4.29$ & $1.77 \pm 3.51$ & \\
\hline
\end{tabular}

*Significant difference between two groups

P-E: prosthesis-endplate; $\mathrm{PHO}$, posterior heterotopic ossification; post-op, values at 1 week after surgery; FSU, functional spinal unit; ROM, range of motion

that $\mathrm{HO}$ was more prone to occur when the uncovered sagittal distance $\geq 2.5 \mathrm{~mm}$. Another study by Guo et al. [16] also revealed that the HO occurrence was significantly related with footprint matching degree using
Table 6 Radiographic parameters between low disc height change group and high disc height change group

\begin{tabular}{|c|c|c|c|}
\hline & $\begin{array}{l}\text { Disc height } \\
\text { change }<1.80 \\
(n=67)\end{array}$ & $\begin{array}{l}\text { Disc height } \\
\text { change } \geq 1.80 \\
(n=107)\end{array}$ & $P$ value \\
\hline $\mathrm{PHO}$ & 13 & 60 & $<0.001^{*}$ \\
\hline $\begin{array}{l}\text { Motion-restricting } \\
\mathrm{PHO}\end{array}$ & 2 & 23 & 0.196 \\
\hline \multicolumn{4}{|l|}{ Post-op } \\
\hline Cervical lordosis & $13.19 \pm 10.58$ & $14.11 \pm 10.40$ & 0.497 \\
\hline $\mathrm{ROM} C 2-\mathrm{C} 7$ & $30.41 \pm 12.02$ & $27.75 \pm 10.61$ & 0.131 \\
\hline Shell angle & $3.71 \pm 4.70$ & $5.17 \pm 5.17$ & 0.063 \\
\hline FSU angulation & $2.13 \pm 4.03$ & $3.20 \pm 5.08$ & 0.145 \\
\hline $\begin{array}{l}\text { ROM at index } \\
\text { level }\end{array}$ & $7.59 \pm 3.71$ & $6.98 \pm 3.77$ & 0.316 \\
\hline \multicolumn{4}{|l|}{ Last follow-up } \\
\hline Cervical lordosis & $9.93 \pm 8.90$ & $13.27 \pm 8.37$ & $0.013^{*}$ \\
\hline $\mathrm{ROM} C 2-\mathrm{C} 7$ & $49.49 \pm 14.06$ & $48.56 \pm 13.69$ & 0.664 \\
\hline Shell angle & $1.68 \pm 4.87$ & $1.66 \pm 5.17$ & 0.982 \\
\hline FSU angulation & $-0.66 \pm 4.78$ & $0.29 \pm 4.69$ & 0.198 \\
\hline $\begin{array}{l}\text { ROM at index } \\
\text { level }\end{array}$ & $8.61 \pm 5.02$ & $8.04 \pm 4.77$ & 0.588 \\
\hline Anterior bone loss & 40 & 67 & 0.701 \\
\hline \multicolumn{4}{|l|}{$\begin{array}{l}\text { Changes during } \\
\text { follow-up }\end{array}$} \\
\hline Cervical lordosis & $-3.26 \pm 9.12$ & $-0.84 \pm 8.89$ & 0.086 \\
\hline Shell angle & $-2.03 \pm 3.77$ & $-3.51 \pm 4.16$ & $0.019^{*}$ \\
\hline FSU angulation & $-2.79 \pm 3.19$ & $-2.91 \pm 3.88$ & 0.817 \\
\hline Insertion angle & $0.97 \pm 3.77$ & $1.41 \pm 4.03$ & 0.462 \\
\hline
\end{tabular}

*Significant difference between two groups

PHO, posterior heterotopic ossification; post-op, values at 1 week after surgery; FSU, functional spinal unit; ROM, range of motion

three-dimensional computed tomographic images. In this study, the poor endplate coverage group with 
Table 7 Radiographic parameters between low CP group and high CP group

\begin{tabular}{|c|c|c|c|}
\hline & $\mathrm{CP}<84.88(n=58)$ & $\mathrm{CP} \geq 84.88(n=116)$ & $P$ value \\
\hline $\mathrm{PHO}$ & 45 & 28 & $<0.001^{*}$ \\
\hline Motion-restricting PHO & 19 & 6 & 0.069 \\
\hline \multicolumn{4}{|l|}{ Post-op } \\
\hline Cervical lordosis & $12.12 \pm 9.91$ & $14.57 \pm 10.66$ & 0.211 \\
\hline $\mathrm{ROM} C 2-\mathrm{C} 7$ & $29.51 \pm 11.55$ & $28.40 \pm 11.08$ & 0.677 \\
\hline Shell angle & $4.70 \pm 5.24$ & $4.56 \pm 4.95$ & 0.632 \\
\hline FSU angulation & $3.20 \pm 4.97$ & $2.59 \pm 4.60$ & 0.424 \\
\hline ROM at index level & $8.07 \pm 4.07$ & $6.78 \pm 3.52$ & $0.029^{*}$ \\
\hline \multicolumn{4}{|l|}{ Last follow-up } \\
\hline Cervical lordosis & $11.92 \pm 8.70$ & $12.01 \pm 8.74$ & 0.945 \\
\hline $\mathrm{ROM} C 2-\mathrm{C} 7$ & $44.83 \pm 13.96$ & $50.96 \pm 13.31$ & $0.018^{*}$ \\
\hline Shell angle & $1.83 \pm 5.78$ & $1.58 \pm 4.66$ & 0.759 \\
\hline FSU angulation & $0.69 \pm 4.75$ & $-0.46 \pm 4.70$ & 0.134 \\
\hline ROM at index level & $6.89 \pm 4.70$ & $8.94 \pm 4.82$ & $0.004^{*}$ \\
\hline Anterior bone loss & 32 & 75 & 0.226 \\
\hline \multicolumn{4}{|l|}{ Changes during follow-up } \\
\hline Cervical lordosis & $-0.20 \pm 8.70$ & $-2.56 \pm 9.12$ & 0.104 \\
\hline Shell angle & $-2.87 \pm 3.96$ & $-2.98 \pm 4.14$ & 0.874 \\
\hline FSU angulation & $-2.51 \pm 3.61$ & $-3.04 \pm 3.63$ & 0.263 \\
\hline Insertion angle & $0.85 \pm 4.64$ & $1.43 \pm 3.51$ & 0.260 \\
\hline
\end{tabular}

*Significant difference between two groups

$\mathrm{CP}$, combined parameter; $\mathrm{PHO}$, posterior heterotopic ossification; post-op, values at 1 week after surgery; FSU, functional spinal unit; ROM, range of motion

prosthesis-endplate depth ratio $<93.77 \%$ suggested a significantly higher incidence of PHO. However, the motion-restricting $\mathrm{PHO}$ rates were not significantly different between the better and poor endplate coverage group. This is consistent with the study of Kim et al. [18] that endplate coverage was not significantly related to the ROM-limiting $\mathrm{HO}$, which probably indicating a distinct mechanism for high-grade $\mathrm{HO}$ and need to be further investigated. They also found that the increased segmental ROM was related to the formation of highgrade HO. However, a meta-analysis of 1674 patients found that neither $\mathrm{HO}$ nor the high-grade $\mathrm{HO}$ was associated with the segmental ROM [31]. Although our study found a significantly larger segmental ROM after surgery and smaller change in disc insertion angle in the poor endplate coverage group, we believe the minor differences between the two groups not reaching clinical significance. Tian et al. [24] found that patients with progressed HO showed greater change in disc insertion angle by retrospectively reviewing patients who underwent CDR with Bryan. The use of different types of implants may explain the discrepancy. A finite element analysis found that the endplate stress was much higher in the models with Prestige-LP and ProDisc-C, compared with the model with Bryan [32]. That is, the biomechanics of the artificial itself also have an impact on $\mathrm{HO}$ formation and further investigations with large patient sample and different prosthesis are needed [16, $26,28]$.

HO formation is postulated to compensating for the non-uniform stress distribution, which is one of the mechanical elements associated with the bone remodelling after CDR [13]. HO may occur when the implanted artificial disc fails to restore normal loading patterns in the surgical segment. Previous studies suggested a significantly lower incidence of HO after CDR with ProDisc Vivo disc, whose design had the potential benefits of matching the anatomical feature of vertebral endplate and reducing the violation of endplate [33, 34]. Palissery et al. [35] found that the use of smaller size artificial discs caused localized stress concentration in the implant-bony endplate interface while a well-fitting prosthesis contributed to a more physiological and uniform stress distribution through finite element analysis. Ganbat et al. [13] developed a three-dimensional finite element model simulating a bone adaptation process after CDR and found that most of the $\mathrm{HO}$ developed on the vertebral endplates uncovered by the prosthesis footplate under compressive force. Interestingly, $\mathrm{HO}$ formation itself reduced the peak values and total values of the strain energy of the endplate, which is more obvious in the posterior disc region without footplate coverage. Since an artificial disc may 
not cover the whole vertebral endplate because of surgical restriction, the prosthesis-endplate depth ratio less than $93.8 \%$ should be avoided according to our results.

Insufficient endplate coverage leads to non-uniform stress pattern in the margin of prosthesis, which may be exacerbated by larger intervertebral height change postoperatively. Although increase in intervertebral height is conducive to the neurological decompression, inappropriate disc height increment may alter the segmental biomechanical environment and increase the stress of prosthesis-endplate interface [14, 19]. The present study showed that intervertebral disc height change was significantly higher in the PHO group, and the most suitable cut-off for disc height change to predict $\mathrm{HO}$ is $1.80 \mathrm{~mm}$. Wang et al. [21] found that the degree of distraction of index level was significantly larger in patients with $\mathrm{HO}$ following CDR. Another study by Kim et al. [18] also identified significantly higher differences in height in the high-grade $\mathrm{HO}$ group than in the low-grade HO group. Our findings suggested that larger disc height distraction was associated with better cervical lordosis at last followup. The change of shell angle during follow-up in the large disc height change group was significantly higher, indicating that the formation of PHO might have been adapted to the change of biomechanical environment after CDR [14, 24]. The combined effects of endplate coverage and intervertebral height were further investigated, and an increased AUC for predicting PHO was suggested in this study. We found that ROM at index level postoperatively was significantly larger in the low CP group, however, limited clinical implication due to the small differences. In addition, uneven loading force in the boneimplant interface of cervical artificial disc was also shown to be related to ABL after CDR. Chen et al. [36] revealed that increasing the shell angle may increase the incidence of ABL after CDR because of the decreased loading force in anterior space. This study suggested that ABL seemed not related to the biomechanics caused by changes of endplate coverage and intervertebral height, which probably contributed more to the posterior biomechanical environment. Therefore, detailed stress distribution caused by different endplate coverage and intervertebral height change is needed further investigation.

The limitations of the present study deserve consideration. First, the retrospective nature presented inherent weakness. Second, the minimum of 2-year follow-up was relatively short and the incidence of $\mathrm{HO}$ might be underestimated. Third, although the radiological parameters were collected according to the previously published literature, it should be acknowledged that the inherent potential of error in radiographic imaging may be a major limitation of this study. Fourth, the single institution study and prosthesis type limited the generalizability of the results. Thus, multicentre, prospective studies with long-term follow-up and various disc types are needed. Despite these limitations, this is the first study to focus on the effect of segmental biomechanics due to variations of endplate coverage and interverbal disc height after $\mathrm{CDR}$ on $\mathrm{HO}$ formation through quantitative analysis.

\section{Conclusions}

Inadequate endplate coverage and excessive change of intervertebral height are both critical risk factors for the PHO formation after CDR while have no effect on ABL. Endplate coverage less than $93.8 \%$ or intervertebral height change more than $1.8 \mathrm{~mm}$ would increase the risk of PHO. The combination of these two factors may exacerbate the non-uniform distribution of stress in the boneimplant interface and promote $\mathrm{HO}$ formation. At least one of the two issues should be avoided during surgery to prevent the occurrence of $\mathrm{HO}$.

\section{Abbreviations \\ ACDF: Anterior cervical discectomy and fusion; CDR: Cervical disc replace- ment; ASD: Adjacent segment disease; HO: Heterotopic ossification; JOA: Japa- nese Orthopaedic Association; NDI: Neck Disability Index; VAS: Visual analogue scale; ABL: Anterior bone loss; PHO: Posterior heterotopic ossification; CT: Computed tomography; ROM: Range of motion; FSU: Functional spinal unit; ROC: Receiver operating characteristic; AUC: Area under the curve.}

\section{Acknowledgements}

We would like to thank the person who gave assistance to this study.

\section{Authors' contributions}

YWS and YY contributed equally to this study. YWS conducted the design of the study and drafted the manuscript with the help from $Y Y, H L$, and BYW.

$Y Y$ and $X R$ helped in the statistical analysis. $X R, H L$, and $Y Y$ conducted the interpretation of data. $\mathrm{HL}, \mathrm{YM}$, and $\mathrm{YH}$ contributed to the revision. The authors have read and approved the final manuscript.

\section{Funding}

The study was supported by research grants from the 1.3.5 project for disciplines of excellence, West China Hospital, Sichuan University (ZYJC18029), and the Sichuan Province Science and Technology Support Program of China (NO.2020YFS0077).

\section{Availability of data and materials}

The datasets used in this study are available from the corresponding author on reasonable request.

\section{Declarations}

Ethics approval and consent to participate

The study protocol was approved by the Medical Ethical Committee of West China Hospital of Sichuan University and was conducted following the 1964 Helsinki Declaration and its later amendments or comparable ethical standards. All patients provided signed, informed consent prior to study participation.

\section{Consent for publication}

Not applicable.

\section{Competing interests}

The authors declare that they have no competing interests. 


\section{Author details}

'Department of Orthopedic Surgery, West China Hospital, Sichuan University, No. 37 Guo Xue Rd, Chengdu 610041, China. ${ }^{2}$ Department of Operation Room and Anesthesia Center, West China Hospital, Sichuan University, No. 37 Guo Xue Rd, Chengdu 610041, China.

Received: 28 August 2021 Accepted: 12 November 2021 Published online: 25 November 2021

\section{References}

1. Eck JC, Humphreys SC, Lim TH, Jeong ST, Kim JG, Hodges SD et al. Biomechanical study on the effect of cervical spine fusion on adjacentlevel intradiscal pressure and segmental motion. Spine (Phila Pa 1976). 2002;27(22):2431-4. https://doi.org/10.1097/00007632-200211150-00003.

2. Lavelle WF, Riew KD, Levi AD, Florman JE. Ten-year outcomes of cervical disc replacement with the BRYAN cervical disc: results from a Prospective, randomized, controlled clinical trial. Spine (Phila Pa 1976). 2019;44(9):60108. https://doi.org/10.1097/BRS.0000000000002907.

3. Findlay C, Ayis S, Demetriades AK. Total disc replacement versus anterior cervical discectomy and fusion: a systematic review with meta-analysis of data from a total of 3160 patients across 14 randomized controlled trials with both short- and medium- to long-term outcomes. Bone Jt J. 2018;100-B(8):991-1001. https://doi.org/10.1302/0301-620X.100B8.BJJ2018-0120.R1

4. Parish JM, Coric D. Cervical arthroplasty: long-term outcomes of FDA IDE trials. Global Spine J. 2020;10(2 Suppl):61S-64S. https://doi.org/10.1177/ 2192568219898154

5. Guo H, Sheng J, Sheng WB, Liang WD, Wang J, Xun CH. An eight-year follow-up study on the treatment of single-level cervical spondylosis through intervertebral disc replacement and anterior cervical decompression and fusion. Orthop Surg. 2020;12(3):717-26. https://doi.org/10. 1111/os.12634

6. Tian W, Fan M-X, Liu Y-j, Han X, Yan K, Wang H et al. An analysis of paravertebral ossification in cervical artificial disc replacement: a novel classification based on computed tomography. Orthop Surg. 2016;8(4):440-46. https://doi.org/10.1111/os.12286.

7. Zhou F, Ju KL, Zhao Y, Zhang F, Pan S, Heller JG et al. Progressive bone formation after cervical disc replacement: minimum of 5-year follow-up. Spine (Phila Pa 1976). 2018;43(3):E163-70. https://doi.org/10.1097/BRS. 0000000000002264

8. Virk S, Phillips F, Khan S, Qureshi S. A cross-sectional analysis of 1347 complications for cervical disc replacements from medical device reports maintained by the United States Food and Drug Administration. Spine J. 2021;21(2):265-72. https://doi.org/10.1016/j.spinee.2020.09.005.

9. Nunley PD, Cavanaugh DA, Kerr EJ, 3rd, Utter PA, Campbell PG, Frank KA et al. Heterotopic ossification after cervical total disc replacement at 7 years-prevalence, progression, clinical implications, and risk factors. Int J Spine Surg 2018;12(3):352-61. https://doi.org/10.14444/5041.

10. Kim K, Hoffman G, Bae H, Redmond A, Hisey M, Nunley P, et al. Tenyear outcomes of 1 - and 2-level cervical disc arthroplasty from the Mobi-C investigational device exemption clinical trial. Neurosurgery. 2021;88(3):497-505. https://doi.org/10.1093/neuros/nyaa459.

11. Wang H, Wang $X$, Liu H, Meng Y, Guo Y, Hong Y. Risk factors for high-grade heterotopic ossification after total disc replacement: a single-center experience of 394 cases. Neurosurgery. 2021. https://doi.org/10.1093/ neuros/nyab298.

12. Tu TH, Wu JC, Huang WC, Wu CL, Ko CC, Cheng $\mathrm{H}$. The effects of carpentry on heterotopic ossification and mobility in cervical arthroplasty: determination by computed tomography with a minimum 2-year follow-up: clinical article. J Neurosurg Spine. 2012;16(6):601-9. https://doi.org/10. 3171/2012.3.SPINE11436.

13. Ganbat D, Kim YH, Kim K, Jin YJ, Park WM. Effect of mechanical loading on heterotopic ossification in cervical total disc replacement: a threedimensional finite element analysis. Biomech Model Mechanobiol. 2016;15(5):1191-9. https://doi.org/10.1007/s10237-015-0752-3.

14. Hui N, Phan K, Kerferd J, Lee M, Mobbs RJ. Cervical total disc replacement and heterotopic ossification: a review of literature outcomes and biomechanics. Asian Spine J. 2021;15(1):127-37. https://doi.org/10.31616/asj. 2019.0234.
15. Zeng J, Liu H, Chen $H$, Rong X, Meng Y, Yang Y et al. Effect of prosthesis width and depth on heterotopic ossification after cervical disc arthroplasty. Spine (Phila Pa 1976). 2019;44(9):624-28. https://doi.org/10.1097/ BRS.0000000000002915.

16. Guo Q, Fang Z, Guan H, Xiong W, Li F. The effect of footprint mismatch on heterotopic ossification after cervical disk replacement. Clin Spine Surg. 2020;33(6):E241-50. https://doi.org/10.1097/bsd.0000000000000943.

17. Xu S, Ou Y, Du X, He B, Li Y, Yu H. Heterotopic ossification after prestige-LP cervical disc arthroplasty is related to insufficient sagittal coverage of the endplate by the prosthesis. Med Sci Monit. 2021;27:e929890. https://doi. org/10.12659/MSM.929890.

18. Kim KS, Heo DH. Do postoperative biomechanical changes induce heterotopic ossification after cervical arthroplasty? A 5-year follow-up study. Clin Spine Surg. 2016;29(6):E309-13. https://doi.org/10.1097/bsd.00000 00000000054.

19. Yuan W, Zhang H, Zhou X, Wu W, Zhu Y. The influence of artificial cervical disc prosthesis height on the cervical biomechanics: a finite element study. World Neurosurg. 2018;113:e490-8. https://doi.org/10.1016/j.wneu. 2018.02.062.

20. Yang MMH, Ryu WHA, Casha S, DuPlessis S, Jacobs WB, Hurlbert RJ. Heterotopic ossification and radiographic adjacent-segment disease after cervical disc arthroplasty. J Neurosurg Spine. 2019:1-10. https://doi.org/ 10.3171/2019.5.Spine19257.

21. Wang XF, Liu H, Meng Y, Hong Y, Wang BY, Ding C, et al. Effect of disC height and degree of distraction on heterotopic ossification after cervical disc replacement. World Neurosurg. 2021;145:E100-7. https://doi.org/10. 1016/j.wneu.2020.09.134

22. Zhou F, Li S, Zhao Y, Zhang Y, Ju KL, Zhang F et al. Quantitative analysis of the correlation between preoperative cervical degeneration and postoperative heterotopic ossification after cervical disc replacement: minimum 10-year follow-up data. J Neurosurg Spine. 2020:1-6. https://doi.org/10. 3171/2020.4.SPINE191303.

23. Kieser DC, Cawley DT, Fujishiro T, Mazas S, Boissiere L, Obeid I, et al. Risk factors for anterior bone loss in cervical disc arthroplasty. J Neurosurg Spine. 2018;29(2):123-9. https://doi.org/10.3171/2018.1.SPINE171018.

24. Tian W, Han X, Liu B, He D, Lv Y, Yue J. Generation and development of paravertebral ossification in cervical artificial disk replacement: a detailed analytic report using coronal reconstruction CT. Clin Spine Surg. 2017;30(3):E179-88. https://doi.org/10.1097/bsd.0000000000000044.

25. Cho HJ, Shin MH, Huh JW, Ryu KS, Park CK. Heterotopic ossification following cervical total disc replacement: iatrogenic or constitutional? Korean J Spine. 2012;9(3):209-14. https://doi.org/10.14245/kjs.2012.9.3. 209.

26. Jin YJ, Park SB, Kim MJ, Kim KJ, Kim HJ. An analysis of heterotopic ossification in cervical disc arthroplasty: a novel morphologic classification of an ossified mass. Spine J. 2013;13(4):408-20. https://doi.org/10.1016/j.spinee 2012.11.048.

27. Genitiempo M, Perna A, Santagada DA, Meluzio MC, Proietti L, Bocchi $M B$, et al. Single-level Bryan cervical disc arthroplasty: evaluation of radiological and clinical outcomes after 18 years of follow-up. Eur Spine J. 2020;29(11):2823-30. https://doi.org/10.1007/s00586-020-06486-5.

28. Yang X, Donk R, Bartels R, Arts MP, Depreitere B, Vleggeert-Lankamp CLA. Comparing heterotopic ossification in two cervical disc prostheses. Spine (Phila Pa 1976). 2020;45(19):1329-34. https://doi.org/10.1097/BRS.00000 00000003537.

29. Yao Q, Yin P, Khan K, Tsai TY, Li JS, Hai Y, et al. Differences of the morphology of subaxial cervical spine endplates between Chinese and white men and women. Biomed Res Int. 2018;2018:2854175. https://doi.org/10. $1155 / 2018 / 2854175$.

30. Thaler M, Hartmann S, Gstottner M, Lechner R, Gabl M, Bach C. Footprint mismatch in total cervical disc arthroplasty. Eur Spine J. 2013;22(4):75965. https://doi.org/10.1007/s00586-012-2594-3.

31. Hui N, Phan K, Lee MY, Kerferd J, Singh T, Mobbs RJ. The changes in cervical biomechanics after CTDR and its association with heterotopic ossification: a systematic review and meta-analysis. Glob Spine J. 2020:2192568220922949. https://doi.org/10.1177/2192568220922949.

32. Lin CY, Kang H, Rouleau JP, Hollister SJ, Marca FL. Stress analysis of the interface between cervical vertebrae end plates and the Bryan, Prestige $L P$, and ProDisc- $C$ cervical disc prostheses: an in vivo image-based finite element study. Spine (Phila Pa 1976). 2009;34(15):1554-60. https://doi. org/10.1097/BRS.0b013e3181aa643b. 
33. Mehren C, Wuertz-Kozak K, Sauer D, Hitzl W, Pehlivanoglu T, Heider F. Implant design and the anchoring mechanism influence the incidence of heterotopic ossification in cervical total disc replacement at 2-year follow-up. Spine (Phila Pa 1976). 2019;44(21):1471-80. https://doi.org/10. 1097/BRS.0000000000003098.

34. Cao S, Zhao Y, Sun Y, Li W, Zhou F, Zhang F et al. Single-level cervical arthroplasty with prodisc-C vivo artificial disc: five-year follow-up results from one center. Spine (Phila Pa 1976). 2021. https://doi.org/10.1097/brs. 0000000000004119

35. Palissery V, Mulholland RC, McNally DS. The implications of stress patterns in the vertebral body under axial support of an artificial implant. Med Eng
Phys. 2009;31(7):833-7. https://doi.org/10.1016/j.medengphy.2009.03. 010.

36. Chen TY, Chen WH, Tzeng CY, Huang CW, Yang CC, Chen HT, et al. Anterior bone loss after cervical Bryan disc arthroplasty: insight into the biomechanics following total disc replacement. Spine J. 2020;20(8):1211-8. https://doi.org/10.1016/j.spinee.2020.04.017.

\section{Publisher's Note}

Springer Nature remains neutral with regard to jurisdictional claims in published maps and institutional affiliations.
Ready to submit your research? Choose BMC and benefit from:

- fast, convenient online submission

- thorough peer review by experienced researchers in your field

- rapid publication on acceptance

- support for research data, including large and complex data types

- gold Open Access which fosters wider collaboration and increased citations

- maximum visibility for your research: over 100M website views per year

At BMC, research is always in progress.

Learn more biomedcentral.com/submissions 